\title{
Taxol Inhibits Neointimal Smooth Muscle Cell Accumulation after Angioplasty in the Rat
}

\author{
Steven J. Sollott, * Linda Cheng, * Rebecca R. Pauly, * G. Mark Jenkins, * Robert E. Monticone, * Masafumi Kuzuya, * \\ Jeffrey P. Froehlich, * Michael T. Crow, * Edward G. Lakatta, * Eric K. Rowinsky, ${ }^{\star}$ and James L. Kinsella* \\ * Laboratory of Cardiovascular Science, Gerontology Research Center, National Instituite on Aging, National Institutes of Health, \\ Baltimore, Maryland 21224; and ${ }^{\ddagger}$ Division of Pharmacology and Experimental Therapeutics, Johns Hopkins Oncology Center, \\ Johns Hopkins Medical Institutions, Baltimore, Maryland 21205
}

\begin{abstract}
Despite significant improvements in the primary success rate of the medical and surgical treatments for atherosclerotic disease, including angioplasty, bypass grafting, and endarterectomy, secondary failure due to late restenosis continues to occur in 30-50\% of individuals. Restenosis and the later stages in atherosclerotic lesions are due to a complex series of fibroproliferative responses to vascular injury involving potent growth-regulatory molecules (such as platelet-derived growth factor and basic fibroblast growth factor) and resulting in vascular smooth muscle cell (VSMC) proliferation, migration, and neointimal accumulation. We show here, based on experiments with both taxol and deuterium oxide, that microtubules are necessary for VSMCs to undergo the multiple transformations contributing to the development of the neointimal fibroproliferative lesion. Taxol was found to interfere both with platelet-derived growth factor-stimulated VSMC migration and with VSMC migration and with VSMC proliferation, at nanomolar levels in vitro. In vivo, taxol prevented medial VSMC proliferation and the neointimal VSMC accumulation in the rat carotid artery after balloon dilatation and endothelial denudation injury. This effect occurred at plasma levels approximately two orders of magnitude lower than that used clinically to treat human malignancy (peak levels achieved in this model were $\sim 50-60 \mathrm{nM}$ ). Taxol may therefore be of therapeutic value in preventing human restenosis with minimal toxicity. (J. Clin. Invest. 1995. 95:1869-1876.) Key words: restenosis $\bullet$ atherosclerosis $\bullet$ microtubules $\bullet$ tubulin - deuterium oxide
\end{abstract}

\section{Introduction}

Microtubules, ubiquitous cellular constituents present in all eukaryotic cells, are required for normal cellular activities. They are an essential component of the mitotic spindle needed for cell division and are required for maintaining cell shape and a variety of other cellular activities, such as motility, anchorage, transport between cellular organelles, extracellular secretory

Address correspondence to James L. Kinsella, Ph.D., Laboratory of Cardiovascular Science, Gerontology Research Center, National Institute on Aging, 4940 Eastern Avenue, Baltimore, MD 21224. Phone: 410-558-8202; FAX: 410-558-8150.

Received for publication 3 March 1994 and in revised form 7 December 1994.

The Journal of Clinical Investigation, Inc.

Volume 95, April 1995, 1869-1876 processes (1), modulation of the interactions of growth factors with cell surface receptors, and intracellular signal transduction (2-5). Furthermore, microtubules probably play a critical regulatory role in cell replication, as both the c-mos oncogene and CDC-2-kinase, which regulate entry into mitosis, bind to and phosphorylate tubulin $(6,7)$ and the product of both the tumor suppressor gene p53 and the T-antigen of simian virus 40 bind tubulin in a ternary complex (8). Microtubules are in dynamic equilibrium with their soluble protein subunits, the $\alpha$ - and $\beta$ tubulin heterodimers (1). Assembly under physiologic conditions requires GTP and certain microtubule-associated and -organizing proteins as cofactors; on the other hand, high calcium and cold temperature cause depolymerization.

Interference with this normal equilibrium between the microtubule and its subunits would therefore be expected to disrupt cell division and motility, as well as other activities dependent on microtubules. This strategy has been used with significant success in the treatment of certain malignancies. Indeed, antimicrotubule agents are among the most important anticancer drugs currently used. The vinca alkaloids, which promote microtubule disassembly, play principal roles in the chemotherapy of most curable neoplasms, including acute lymphocytic leukemia, Hodgkin's and non-Hodgkin's lymphomas, and germ cell tumors, as well as in the palliative treatment of many other cancers.

The newest and most promising antimicrotubule agent under research is taxol. Taxol, the prototype of the taxane class of compounds, is a highly derivatized diterpenoid (9) isolated from the bark from the Pacific yew, Taxus brevifolia. Taxol induces tubulin polymerization, resulting in the formation of abnormally stable and nonfunctional microtubules $(10,11)$. This is a novel mechanism compared with classic antimicrotubule agents such as colchicine and the vinca alkaloids, which induce microtubule disassembly. Taxol has one of the broadest spectra of antineoplastic activity, renewing serious interest in chemotherapeutic strategies directed against, microtubules (for review, see reference 12). In recent phase II studies, taxol has shown significant activity in advanced and refractory ovarian cancer $(13,14)$ and malignant melanoma $(15)$, as well as in cancers of the breast (16), head and neck, and lung.

Despite significant improvements in the primary success rate of the medical and surgical treatments for atherosclerotic disease, including angioplasty, bypass grafting, and endarterectomy, secondary failure due to late restenosis continues to occur in $30-50 \%$ of individuals. During angioplasty, intraarterial balloon catheter inflation results in deendothelialization, disruption of the internal elastic lamina, and probably injury to some medial smooth muscle cells. Although restenosis after such vascular injury likely results from the interdependent actions of the ensuing thrombosis, inflammation, elaboration of potent growth-regulatory molecules (such as PDGF basic fibroblast 
growth factor), and smooth muscle cell accumulation (17), the final common pathway evolves as a result of vascular smooth muscle cell (VSMC) ${ }^{1}$ dedifferentiation from a contractile to a secretory phenotype (18). This involves, principally, VSMC secretion of matrix metalloproteinases, which degrade the surrounding basement membrane (19), proliferation, chemotactic migration into the intima (20-27), and secretion of a large extracellular matrix, forming the neointimal fibroproliferative lesion.

Since the pattern of the VSMC phenotypic dedifferentiation after arterial injury mimics that of neoplastic cells (i.e., abnormal proliferation, growth-regulatory molecule and protease secretion, migration, and basement membrane invasion), we tested the hypothesis that interference with VSMC microtubule function by taxol would inhibit restenosis by preventing neointimal VSMC accumulation. Taxol was found to stabilize microtubule polymerization and to interfere with PDGF-stimulated intracellular signaling, proliferation, and migration, at nanomolar levels in vitro. In vivo, taxol prevented neointimal smooth muscle cell accumulation in the rat carotid artery after balloon dilatation and endothelial denudation injury at plasma levels one to three orders of magnitude lower than peak plasma levels achieved with standard doses and schedules used clinically to treat human malignancy and at pharmacologic exposures substantially lower than those associated with cytotoxic effects in the clinic. Thus, microtubule stabilization offers a potentially viable approach to preventing neointimal VSMC accumulation after injury by interfering with a diverse array of sensitive intracellular processes that are likely to have an important role in the development of restenosis. Although the biology of human restenosis may differ somewhat from that of animal models, particularly in the kinetics of cell proliferation $(28,29)$, the ability of taxol to alter a variety of cellular activities (including intracellular signaling, VSMC proliferation and migration, and potentially matrix production) increases the likelihood of success in preventing human restenosis with minimal toxicity over other strategies based solely on the inhibition of cellular proliferation.

\section{Methods}

Cell culture and immunocytochemistry. Rat VSMCs were isolated and cultured according to techniques previously described (30). VSMCs were isolated by collagenase/elastase enzymatic digestion of the medial layers of the rat aorta obtained from 6-mo-old Wistar rats. The cells were maintained in culture with high glucose DMEM supplemented with 10\% FBS and nonessential amino acids (30). Cell cultures were maintained at $37^{\circ} \mathrm{C}$ in $5 \% \mathrm{CO}_{2}$. Passages 8-16 were used throughout the study. Taxol (added from a 1-mM stock solution in DMSO, Sigma Chemical Co., St. Louis, MO) was soluble in the culture media of treated cells at least to the level of $100 \mathrm{nM}$ (the maximum dose tested). In other experiments requiring deuterium oxide-treated cells, ${ }^{2} \mathrm{H}_{2} \mathrm{O}$ (99.9 atom \% deuterium, low tritium; Aldrich Chemical Co., Milwaukee, WI) was substituted ( $\mathrm{vol} / \mathrm{vol})$ for $\mathrm{H}_{2} \mathrm{O}$ in the preparation of the DMEM from concentrated stock. The degree of tubulin polymerization in these cells, after pretreatment for $18 \mathrm{~h}$ with taxol, ${ }^{2} \mathrm{H}_{2} \mathrm{O}$, or control media in culture, was assessed via indirect immunostaining; cells were fixed after pretreatment in $3.7 \%$ formaldehyde and permeabilized with

1. Abbreviations used in this paper: $\mathrm{BrdU}$, bromodeoxyuridine; $\mathrm{IC}_{50}$, concentration producing $50 \%$ inhibition; PDGF, platelet-derived growth factor; VSMC, vascular smooth muscle cell.
$1 \%$ Triton X-100. Polymerized tubulin was labeled with mouse anti- $\beta$ tubulin antibody (mAb SMI 62 against polymerized $\beta$-tubulin; Paragon Biotec, Inc., Baltimore, MD). Secondary labeling was achieved with silver-enhanced, 1-nm gold-conjugated rabbit anti-mouse antibody (Goldmark Biologicals, Phillipsburg, NJ).

In vitro chemoinvasion. Chemoinvasion assays were performed using a modified Boyden chamber (31), consisting of an upper chamber separated from a lower chamber by a porous polyvinylpyrrolidone-free filter. PVPF filters ( 8- $\mu \mathrm{m}$ pore diameter; Nucleopore Filters, Pleasanton, CA) were coated and air dried consecutively with solutions containing $5 \mu \mathrm{g}$ of type I collagen, $5 \mu \mathrm{g}$ of fibronectin, and $10 \mu \mathrm{g}$ of reconstituted basement membrane (produced from the Englebreth-Holm-Swarm tumor [32]), producing a continuous $10-\mu \mathrm{m}$-thick coating of matrix material. Boyden chambers were assembled with PDGF-BB $(10 \mathrm{ng} / \mathrm{ml}$ in DMEM in the lower [chemoattractant] chamber); then cells $(200,000)$ suspended in DMEM containing $0.1 \%$ BSA were added to the upper chamber. Some of the cells used in these assays were pretreated for 18 $\mathrm{h}$ with taxol at concentrations of $30 \mathrm{pM}$ to $100 \mathrm{nM}$ in culture; these concentrations affected neither cell viability (as assessed by trypan blue exclusion) nor cell attachment onto type I collagen-coated surfaces. In the taxol-treated groups, taxol was added to the upper and lower chambers at the same concentration as that used for pretreatment. Some of the cells used in these assays were pretreated for $18 \mathrm{~h}$ with ${ }^{2} \mathrm{H}_{2} \mathrm{O}(25$, 50 , or $75 \%$ [ $\mathrm{vol} / \mathrm{vol}$ ] substitution for $\mathrm{H}_{2} \mathrm{O}$ ) in culture. In the ${ }^{2} \mathrm{H}_{2} \mathrm{O}$ treated groups, ${ }^{2} \mathrm{H}_{2} \mathrm{O}$-substituted DMEM (vol/vol) was added to the upper and lower chambers at the same concentration as that used for pretreatment. In each of these experiments, the chambers were then incubated for $4 \mathrm{~h}$ at $37^{\circ} \mathrm{C}$ in a humidified $5 \% \mathrm{CO}_{2}$ atmosphere. Insignificant cellular proliferation occurs (i.e., VSMC number remains essentially constant) during the 4-h time course of these assays. At the conclusion of the experiment, the filters were removed and the cells were fixed and stained with hematoxylin and eosin. After the cells on the upper surface of the filter (noninvaders) were mechanically removed, the cells on the underside (invaders) were counted under $\times 400$ (four random fields were counted per filter, all experiments were run in triplicate, and each triplicate assay was repeated three times on separate occasions using different VSMC preparations). Chemotaxis was assayed in analogous fashion in the Boyden chambers previously described, except that the reconstituted basement membrane was omitted. We have previously shown that these Boyden assays specifically measure VSMC chemotaxis to a PDGF gradient (rather than chemokinesis), since no significant migration occurs when equal concentrations of PDGF are placed on both sides of the filter barrier or when PDGF is replaced by a nonspecific agent such as BSA (19).

Metalloproteinase activity. Gelatinase zymography was performed on the supernatants removed after the 4-h conclusion of the Boyden assays. Gelatin-degrading metalloproteinases (including the 72-kD type IV collagenase) secreted into the media by VSMCs were detected with SDS-PAGE using gels containing $0.1 \%$ gelatin. Gelatinase activity was then reconstituted in $2.5 \%$ Triton $\mathrm{X}-100$ for $30 \mathrm{~min}$ at $23^{\circ} \mathrm{C}$, followed by $0.2 \mathrm{M} \mathrm{NaCl}, 5 \mathrm{mM} \mathrm{CaCl}, 0.02 \%$ BRIJ 30 (Sigma Chemical Co., St. Louis, MO), $50 \mathrm{mM}$ Tris- $\mathrm{HCl}, \mathrm{pH} 7.6$, for $18 \mathrm{~h}$ at $37^{\circ} \mathrm{C}$. Gelatinolytic activity was observed in gels stained with $0.5 \%$ Coomassie brilliant blue G-250 (destaining was with $10 \%$ acetic acid, $40 \%$ methanol) as a colorless band against a background of blue-stained, nondegraded gelatin.

Measurement of DNA synthesis. $\left[{ }^{3} \mathrm{H}\right]$ Thymidine incorporation was measured to determine the effect of taxol on VSMC DNA synthesis. VSMCs, pretreated with the various concentrations of taxol for $18 \mathrm{~h}$ (and throughout the assay), were plated at $4.5 \times 10^{4}$ on 24-well plates. After a 5-h incubation in 10\% FCS + DMEM, $0.5 \mathrm{mCi}$ of $\left[{ }^{3} \mathrm{H}\right]-$ thymidine was added and the incubation was continued for an additional $16 \mathrm{~h}$. Cells were washed twice with PBS, extracted with $10 \%$ TCA for $2 \mathrm{~h}$ on ice, and centrifuged at $2,000 \mathrm{~g}$ for $10 \mathrm{~min}$. Supernatants were decanted, and pellets were solubilized in $0.5 \mathrm{ml}$ of $1 \mathrm{~N} \mathrm{NaOH}$. After neutralizing with $0.5 \mathrm{ml}$ of $1 \mathrm{~N} \mathrm{HCl},\left[{ }^{3} \mathrm{H}\right]$ thymidine uptake was measured by liquid scintillation counter (Beckman Instr., Fullerton, CA). Each condition of these experiments was performed in triplicate. Incor- 
poration of the thymidine analog bromodeoxyuridine (BrdU) was measured to determine the effect of ${ }^{2} \mathrm{H}_{2} \mathrm{O}$ on VSMC DNA synthesis. VSMCs were plated at $4.5 \times 10^{4}$ on 24-well plates. After a 20-h incubation in $10 \%$ FCS + DMEM at various ${ }^{2} \mathrm{H}_{2} \mathrm{O}$ concentrations, $10 \mu \mathrm{M}$ BrdU was added, and the incubation was continued for an additional $4 \mathrm{~h}$. Cells were washed twice with PBS and fixed with $100 \%$ methanol $\left(-20^{\circ} \mathrm{C}\right)$ for $10 \mathrm{~min}$. The cells were incubated for $2 \mathrm{~h}$ with $1 \mathrm{~N} \mathrm{HCl}$ to denature the DNA and subsequently washed four times in PBS. Mouse anti-BrdU $\mathrm{mAb}$ (Boehringer Mannheim, Indianapolis, IN) in 2\% BSA-PBS was incubated with cells for $1 \mathrm{~h}$. After washing in PBS, goat anti-mouse antibody conjugated with alkaline phosphatase was added. Cell nuclei containing BrdU substituted for thymidine stained red with alkaline phosphatase substrate, whereas all other nuclei stained blue. The fraction of BrdU-positive nuclei was compared in control (defined as $100 \%$ ) and ${ }^{2} \mathrm{H}_{2} \mathrm{O}$-pretreated groups.

Carotid artery injury model. 6-mo-old Wistar rats were anesthetized with $20 \mathrm{mg} / \mathrm{kg}$ body weight pentobarbital, $2 \mathrm{mg} / \mathrm{kg}$ body weight ketamine, and $4 \mathrm{mg} / \mathrm{kg}$ body weight xylazine intraperitoneally under a protocol approved by the National Institute on Aging Animal Care Committee. The left external carotid artery was cannulated with a 2French Fogarty embolectomy catheter, which was then inflated with saline and passed three times up and down the common carotid artery to produce a distending, deendothelializing injury. The animals were treated with $2 \mathrm{mg} / \mathrm{kg}$ body weight taxol in vehicle; control animals were treated with vehicle alone $(13.4 \mathrm{ml} / \mathrm{kg}$ body weight per $\mathrm{d}$ of 1:2:2:165 DMSO/Cremephor EL (Sigma Chemical Co.)/ethanol/PBS) $2 \mathrm{~h}$ after the injury. Taxol or vehicle alone was administered daily for the next $4 \mathrm{~d}$. In other experiments (not involving taxol), rats were equilibrated with $25 \%{ }^{2} \mathrm{H}_{2} \mathrm{O}$ drinking water for 6 wk before carotid injury (a duration estimated to result in $>23 \%{ }^{2} \mathrm{H}_{2} \mathrm{O}$ replacement of body water) and until the carotid arteries were removed for study. After $11 \mathrm{~d}$, the animals were anesthetized as previously described, and the carotid artery was isolated, fixed in $10 \%$ buffered formalin, and embedded in paraffin. Cross sections of the carotids were mounted on microscope slides and stained with hematoxylin and eosin. Morphometric analysis was performed from three to four individual sections from the middle of each injured arterial segment. The image of each carotid artery section was projected onto a digitizing board (SigmaScan, Jandel Scientific, Corte Madera, CA), and the cross-sectional areas of the intima and the media were measured. Experiments were coded so that surgery and data analysis were performed without knowledge of treatment group.

Measurement of in situ VSMC proliferation. In some animals undergoing the carotid artery injury protocol, the effect of taxol versus vehicle on in situ VSMC proliferation was measured via BrdU incorporation at day 2 after injury (approximately the point of maximal VSMC ptoliferation rate after carotid artery balloon injury) (33). Briefly, taxol- and vehicle-treated rats were injected subcutaneously with three doses of BrdU ( $30 \mathrm{mg} / \mathrm{kg}$ ) at 30,38 , and at $46 \mathrm{~h}$ after injury. The carotid artery sections were harvested at $48 \mathrm{~h}$ after injury, and histologic sections were incubated with mouse anti-BrdU mAbs (Boehringer Mannheim) to label BrdU incorporation. Proliferating VSMCs were identified by positive staining with the anti-BrdU antibody. The fraction of BrdU-positive medial VSMC nuclei per cross section (no neointima present at day 2) was compared between taxol and vehicle treatment groups.

Measurement of plasma taxol. Plasma was obtained from pairs of rats at $0.5,1,2,3,4,6$, and $24 \mathrm{~h}$ after treatment with taxol $(2 \mathrm{mg} / \mathrm{kg}$ i.p.) and from two vehicle-treated animals serving as controls and was stored at $-20^{\circ} \mathrm{C}$. Plasma taxol concentrations were measured at The Johns Hopkins Oncology Center (Baltimore, MD) by HPLC using a modification of the method described by Longnecker et al. (34). Briefly, $15 \mu \mathrm{l}$ of $0.1 \mathrm{mmol} /$ liter internal standard ( $n$-cyclohexylbenzamide) was added to a 1-ml plasma sample. Taxol and internal standard were extracted with $5 \mathrm{ml}$ of ethyl acetate, and the organic layer was dried under a nitrogen stream. The residue was reconstituted with $200 \mu \mathrm{l}$ of acetonitrile. $25 \mu \mathrm{l}$ of the solution was injected onto the column using an autosampler. $\mathrm{A} \mathrm{C}_{18}$ column, $150 \times 4.6 \mathrm{~mm}, 5 \mu \mathrm{m}$ (Jones Chromatography, Lakewood, $\mathrm{CO}$ ), with a $\mathrm{C}_{18}$ Guard-Pak precolumn insert (Waters
Chromatography, Marlborough, MA) was used. The separation was achieved at a flow rate of $1.5 \mathrm{ml} / \mathrm{min}$ beginning with $65 \%$ Milli-Q water (Waters Chromatography)/35\% acetonitrile for $6 \mathrm{~min}$, followed by a linear gradient to $35 \%$ Milli-Q water $/ 65 \%$ acetonitrile over $17 \mathrm{~min}$. Ultraviolet detection was performed at $227 \mathrm{~nm}$. The retention times for the internal standard and taxol were 9 and $17.4 \mathrm{~min}$, respectively. The limit of taxol quantification was $0.02 \mu \mathrm{mol} / \mathrm{liter}$, the within-run analytic coefficient of variation was $3 \%$, and the total (between-day) analytic coefficient of variation was $8.5 \%$. Chromatographic data were acquired by and subsequently analyzed using an automated chromatographic data system (PF Nelson 2600; Perkin-Elmer Corp., Cupertino, CA).

\section{Results and Discussion}

Effect of taxol on microtubule polymerization. In in vitro experiments, nanomolar concentrations of taxol (18-h exposure at $37^{\circ} \mathrm{C}$ ) caused a dose-dependent increase in microtubule polymerization in VSMCs cultured on plastic (Fig. 1), cells that also exhibit the dedifferentiated phenotype (30). These results are striking in comparison with the "clinically relevant" micromolar (0.1-10) levels of taxol ordinarily required to cause microtubule bundling in various cultured cancer cell models (35-37). Interestingly, in phase I clinical trials for leukemia, the magnitude of the patient's clinical response to taxol was related to the in vitro sensitivity of leukemic blasts to form microtubule bundles $(38,39)$. Incubating VSMC with $10 \mathrm{nM}$ taxol for $18 \mathrm{~h}$ also led to obvious cell rounding and polyploidy.

Effect of taxol on invasion and metalloproteinase secretion. Boyden chemotactic assays have been used previously to study in vitro tumor cell invasion $(31,32,35)$, and more recently VSMC invasion (19), of basement membrane. This approach was used to evaluate how taxol-induced microtubule polymerization would impair vital cell processes necessary for in vivo neointimal formation, measured as the in vitro ability of cultured VSMCs pretreated with different taxol concentrations ( $30 \mathrm{pM}$ to $100 \mathrm{nM}$ ) to invade filters coated with reconstituted basement membrane proteins in a 4-h Boyden chamber assay (Fig. 2) (19). Using PDGF-BB as an attractant, taxol inhibited VSMC invasion with a half-maximal inhibitory concentration $\left(\mathrm{IC}_{50}\right)$ of $0.5 \mathrm{nM}$. Taxol caused essentially complete inhibition at 100 $\mathrm{nM}$, and significant inhibition was observed at $30 \mathrm{pM}$, the lowest dose used. A chemotaxis assay (filter coated with fibronectin and collagen I but no basement membrane protein barrier) with PDGF-BB as the attractant was performed in an analogous fashion, yielding the identical outcome (data not shown). Whereas cellular invasion of the reconstituted basement membrane protein barrier requires the secretion of specific collagenases (metalloproteinases) by VSMCs (19), as well as by tumor cells in other models $(40,41)$, these collagenases are not required for VSMC chemotaxis (19). These results suggest that taxol, at least at nanomolar drug levels, inhibits VSMC invasion primarily via inhibition of locomotion and/or shape changes, rather than by inhibition of cellular secretion of collagenases. Indeed, gelatinase zymography from these Boyden invasion experiments confirms that the level of VSMC type IV collagenase secretion did not vary significantly over the taxol range of 30 pM to $100 \mathrm{nM}$, compared with control (Fig. 2 inset). Dedifferentiated VSMCs are $\sim 100$ - to 1,000 -fold more sensitive to taxol inhibition than prostate carcinoma cells in a comparable invasion assay (35), as predicted by their respective susceptibilities to taxol-induced microtubule polymerization.

Further support for the concept that microtubule stabilization and hyperpolymerization are the critical and sufficient fac- 

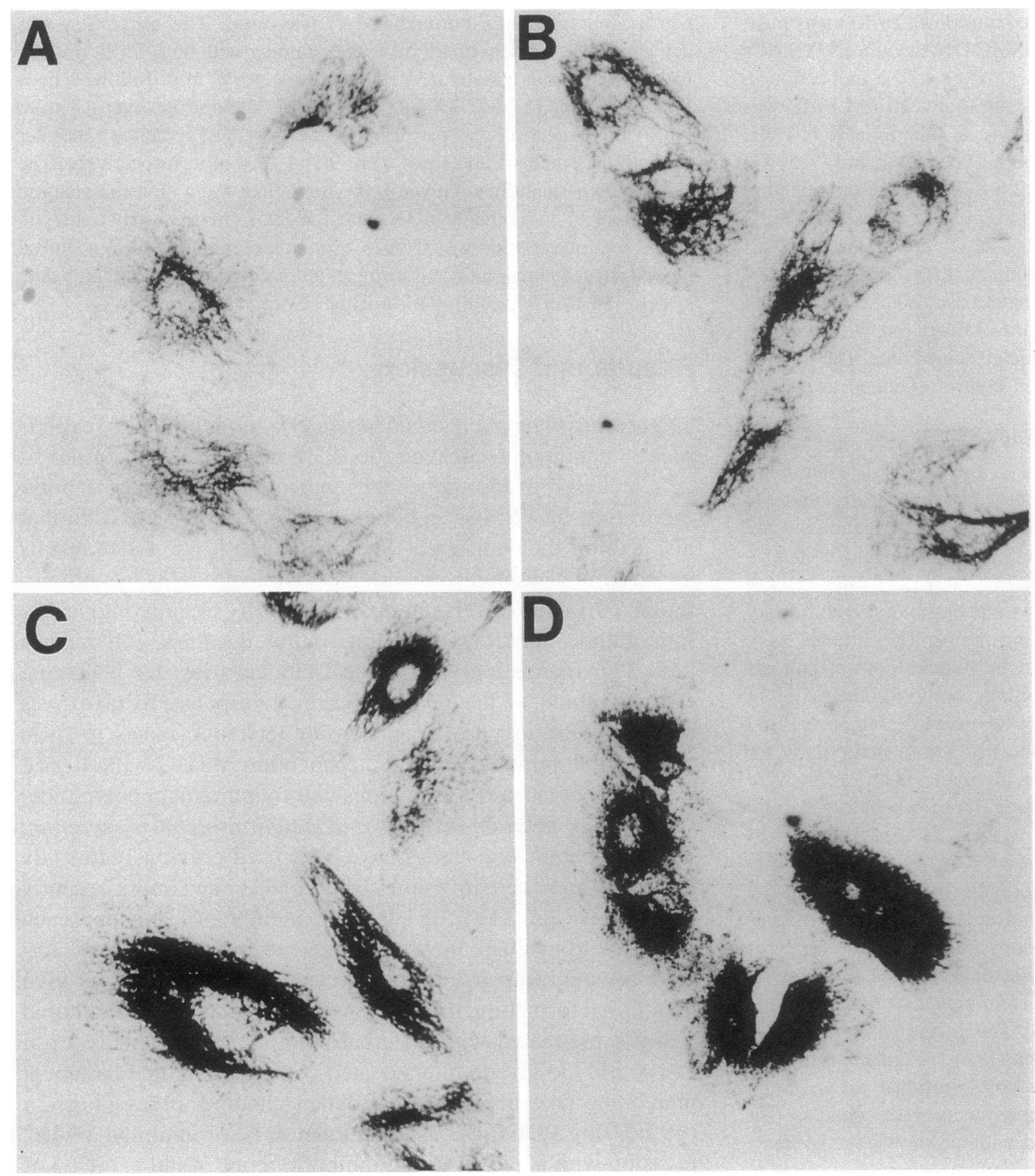

Figure 1. Indirect immunostaining of taxol-induced microtubule bundling in cultured vascular smooth muscle cells. After an 18-h taxol pretreatment in culture, cells were fixed, and polymerized $\beta$-tubulin was labeled with mouse anti- $\beta$-tubulin antibody. Secondary labeling was achieved with silver-enhanced, 1-nm gold-conjugated rabbit anti-mouse antibody. Representative light photomicrographs from $(A)$ control, $(B) 0.1 \mathrm{nM}$ taxol-, $(C) 1 \mathrm{nM}$ taxol-, and $(D) 10$ $\mathrm{nM}$ taxol-treated VSMCs. $\times 450$. tors involved in taxol inhibition of PDGF-directed VSMC invasiveness comes from the results of additional experiments with ${ }^{2} \mathrm{H}_{2} \mathrm{O}$ (heavy water), which enhances microtubule-tubulin polymerization via a mechanism distinct from that of taxol. A combination of the isotope and solvent effects of ${ }^{2} \mathrm{H}_{2} \mathrm{O}$ (42) reversibly increases microtubule polymerization both by reducing the critical concentration for polymerization of $\alpha \beta$-tubulin heterodimers via enhanced tubulin hydrophobic interactions $(43,44)$ and by converting a population of unpolymerizable tubulin to the polymerizable form (45). Pretreating cultured VSMCs for $18 \mathrm{~h}$ with 25,50 , or $75 \%{ }^{2} \mathrm{H}_{2} \mathrm{O}$ caused dose-dependent microtubule hyperpolymerization similar to that observed with taxol (data not shown). This treatment likewise inhibited PDGF-mediated VSMC Boyden chamber invasion in a dosedependent fashion, achieving half-maximal inhibition at $\sim 25 \%$ ${ }^{2} \mathrm{H}_{2} \mathrm{O}$ and nearly complete inhibition at $75 \%{ }^{2} \mathrm{H}_{2} \mathrm{O}$ (Fig. 3).

Effects of taxol on proliferation. In addition to cell recruitment and migration, the various growth-regulatory molecules elaborated after arterial injury, such as PDGF and basic fibroblast growth factor, are also implicated in mitogenesis and cellular proliferation (46-54). Taxol inhibited cultured VSMC $\left[{ }^{3} \mathrm{H}\right]$ thymidine incorporation, an index of cell division, in a dose-dependent fashion, with an $\mathrm{IC}_{50}$ of $5.8 \mathrm{nM}$. Taxol caused essentially complete inhibition at $100 \mathrm{nM}$, and significant inhibition was resolvable at $1 \mathrm{nM}$ (Fig. 2). That this inhibitory profile differs somewhat from that of invasion and chemotaxis, demonstrating $1 \mathrm{log}$-concentration unit lower sensitivity ( $\mathrm{IC}_{50}$ $5.8 \pm 0.6 \mathrm{nM}$ versus $0.5 \pm 0.1 \mathrm{nM}$, respectively, mean $\pm \mathrm{SD}$ [ $n$ $=3$ ], $P<0.001$ ) but with steeper concentration dependence (Hill coefficient $0.80 \pm 0.06$ versus $0.39 \pm 0.04$, respectively, mean \pm SD $[n=3], P<0.001)$, likely arises because of the considerably different roles played by microtubules between these processes. ${ }^{2} \mathrm{H}_{2} \mathrm{O}$, which arrests mitosis in diverse animal and plant cell types $(45,55,56)$ via impairment of the microtubule-organizing centers and thus of microtubule reorganization (57), similarly inhibited cultured VSMC proliferation and DNA synthesis (measured with the thymidine analogue BrdU incorporation into DNA) in a dose-dependent fashion (Fig. 3), consistent with the critical role of microtubule-tubulin dynamics in VSMC proliferation. The rightward-shifted ${ }^{2} \mathrm{H}_{2} \mathrm{O}$ inhibitory profiles of proliferation versus invasion are qualitatively similar to those seen with taxol. 


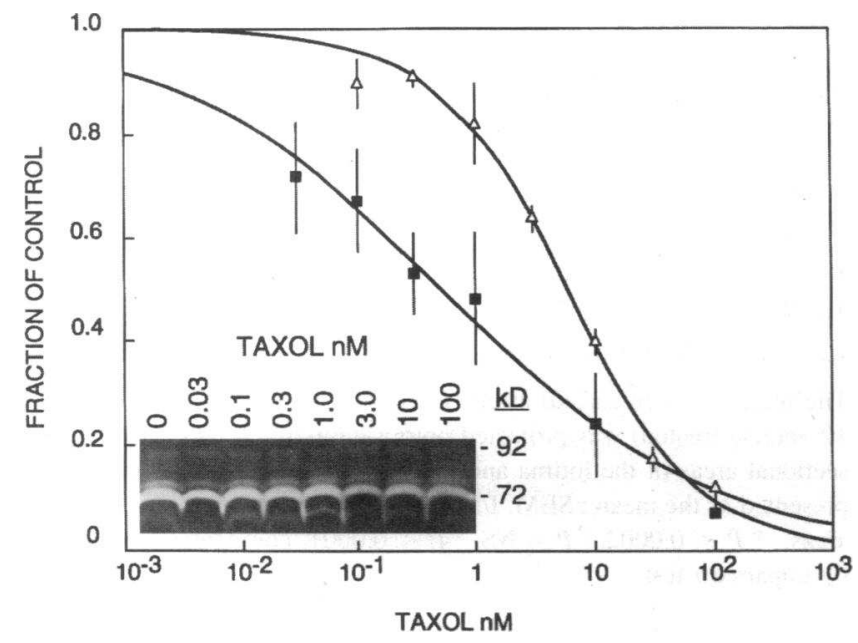

Figure 2. Taxol dose-dependent inhibition of PDGF-BB-directed VSMC chemoinvasion ( $\mathbb{a})$. 4-h chemoinvasion assays were performed using a modified Boyden chamber, seeded with 200,000 cells per well, and PDGF-BB ( $10 \mathrm{ng} / \mathrm{ml})$ as the chemoattractant. Cells were pretreated for $18-\mathrm{h}$ with taxol (concentrations $30 \mathrm{pM}$ to $100 \mathrm{nM}$ ) in culture. All experiments were run in triplicate and were repeated three times on separate occasions using different VSMC preparations. Gelatinase zymograms were performed on the supernatants removed after the 4-h conclusion of the Boyden assays (inset). Gelatin-degrading metalloproteinases (including the $72-\mathrm{kD}$ type IV collagenase) secreted into the medium by VSMCs were detected via SDS-PAGE; gels contained $0.1 \%$ gelatin and were stained with Coomassie Blue. The concave-downward aspect of the $72-\mathrm{kD}$ band is an artifact arising from the presence of BSA in the original Boyden invasion assay and does not otherwise interfere with the 72-kD collagenase band. Taxol dose-dependent inhibition of VSMC DNA synthesis, as indexed by $\left[{ }^{3} \mathrm{H}\right]$ thymidine incorporation $(\Delta)$. Each condition of these experiments was performed in triplicate. Error bars represent \pm SD values.

In the rat, taxol at $2 \mathrm{mg} / \mathrm{kg}$ i.p., which resulted in peak plasma levels of 50-60 nM and trace levels (below the $20 \mathrm{nM}$ HPLC quantitation limit) at $24 \mathrm{~h}$, also inhibited in vivo medial VSMC proliferation (assessed by in situ BrdU labeling) by approximately half versus vehicle alone $(11 \pm 3 \%$ versus $20 \pm 6 \%$, respectively, mean \pm SD $[n=3$ per group], $P<0.05$ ) at day 2 after carotid balloon injury. These levels of inhibition are comparable to those achieved in in vitro conditions. These data are consistent with considerable experimental evidence that normal functional integrity of the microtubules is critical in the transmission of proliferative transmembrane signals from cell surface receptors to the nucleus $(2-5,58-61)$.

Effects of microtubule stabilization on neointimal formation. Thus, taxol significantly inhibits cultured VSMC in vitro invasion and proliferation through interference with microtubule function, disrupting locomotion and the facility to alter shape as well as growth factor-stimulated cell proliferation, at concentrations 10 - to 1,000 -fold lower than peak plasma concentrations achieved in treating human cancers (depending on the duration of the infusion schedule [3-24 h]) (62) and at pharmacological exposures substantially lower than those associated with minimal cytotoxicity in oncologic therapeutics $(63,64)$. This microtubule mechanism is supported by the analogous results of ${ }^{2} \mathrm{H}_{2} \mathrm{O}$ experiments, which exert comparable microtubule effects via different underlying mechanisms. Furthermore, taxol, at doses achieving peak plasma levels approxi-

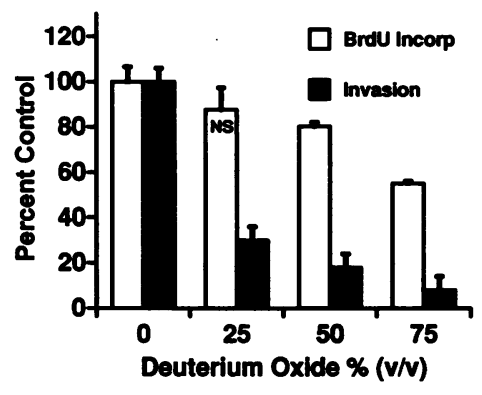

Figure $3 .{ }^{2} \mathrm{H}_{2} \mathrm{O}$ dose-dependent inhibition of DNA synthesis and PDGF-BB-directed VSMC chemoinvasion. 4-h chemoinvasion assays were performed using a modified Boyden chamber, seeded with 200,000 cells per well, and PDGF-BB (10 $\mathrm{ng} / \mathrm{ml}$ ) as the chemoattractant. Cells were pretreated for $18 \mathrm{~h}$ with ${ }^{2} \mathrm{H}_{2} \mathrm{O}$ (concentrations $0,25,50$, and $75 \%$ [ $\mathrm{vol} / \mathrm{vol}$ ] with $\mathrm{H}_{2} \mathrm{O}$ ) in culture (solid bars). All experiments were run in triplicate and were repeated three times on separate occasions using different VSMC preparations. Taxol dose-dependent inhibition of VSMC DNA synthesis, as indexed by the thymidine analogue BrdU incorporation (open bars). Each condition of these experiments was performed in triplicate. Error bars represent $\pm S D$ values. NS, $P$ not significant versus control. All other ${ }^{2} \mathrm{H}_{2} \mathrm{O}$ treatment groups (both chemoinvasion and $\mathrm{BrdU}$ incorporation) were significantly different versus control $(P<0.05)$. Proportionate effects of ${ }^{2} \mathrm{H}_{2} \mathrm{O}$ on chemoinvasion versus BrdU incorporation were significantly different $(P<0.05)$ at each ${ }^{2} \mathrm{H}_{2} \mathrm{O}$ concentration $(25,50$, and $75 \%)$.

mately two orders of magnitude lower than those achieved in humans at doses used clinically to treat human malignancy, significantly inhibited VSMC proliferation measured near the time of its peak occurrence after vascular injury. To determine whether microtubule stabilization/hyperpolymerization could affect in vivo neointimal formation, we administered taxol in a rat model of arterial injury. Taxol administration in vivo $(2 \mathrm{mg} /$ $\mathrm{kg}$ i.p. for $5 \mathrm{~d}$ beginning $2 \mathrm{~h}$ after injury) inhibits the accumulation of neointimal smooth muscle cells in a rat carotid artery balloon catheter injury model, assessed at day 11, compared with vehicle alone (Fig. 4). Quantitative analysis of injured carotid segments showed that taxol treatment reduced the neointimal area by $70 \%$ compared with vehicle-treated animals ( $P$ $<0.0002$ ) (Table I). Several of the taxol-treated animals showed virtually no discernable neointima (in the presence of denuded endothelium, proving injury), whereas all vehicletreated animals demonstrated neointimal thickening. In separate experiments with this carotid injury model, experiments performed in rats $\sim 95 \%$ equilibrated with $25 \%{ }^{2} \mathrm{H}_{2} \mathrm{O}$ demonstrate $\mathrm{a} \sim 40 \%$ reduction in neointimal area compared with normal $\mathrm{H}_{2} \mathrm{O}$-equilibrated control animals $(P<0.05)$ (Fig. 5; Table II), a degree of inhibition comparable to that observed at the same ${ }^{2} \mathrm{H}_{2} \mathrm{O}$ level in the Boyden chamber assay.

Although taxol and ${ }^{2} \mathrm{H}_{2} \mathrm{O}$ potentially affect multiple intracellular processes, the coincidence of their parallel effects on microtubules and on VSMC functionality at multiple levels suggests that microtubule stabilization is the likely mechanism of action, though alternative, unforeseen mechanisms may be responsible for these observed functional changes. Moreover, antimicrotubule agents and particularly those that stabilize and enhance microtubule polymerization, such as taxol, constitute some of the most potent antineoplastic strategies known, probably because of interference with a diverse array of vital cellular functions more critical to the transformed cell compared with the quiescent, differentiated cell. These experiments with taxol and ${ }^{2} \mathrm{H}_{2} \mathrm{O}$ implicate microtubules in the control of the VSMC intracellular mechanisms necessary for promoting the multiple transformations involved in the development of the neointimal 

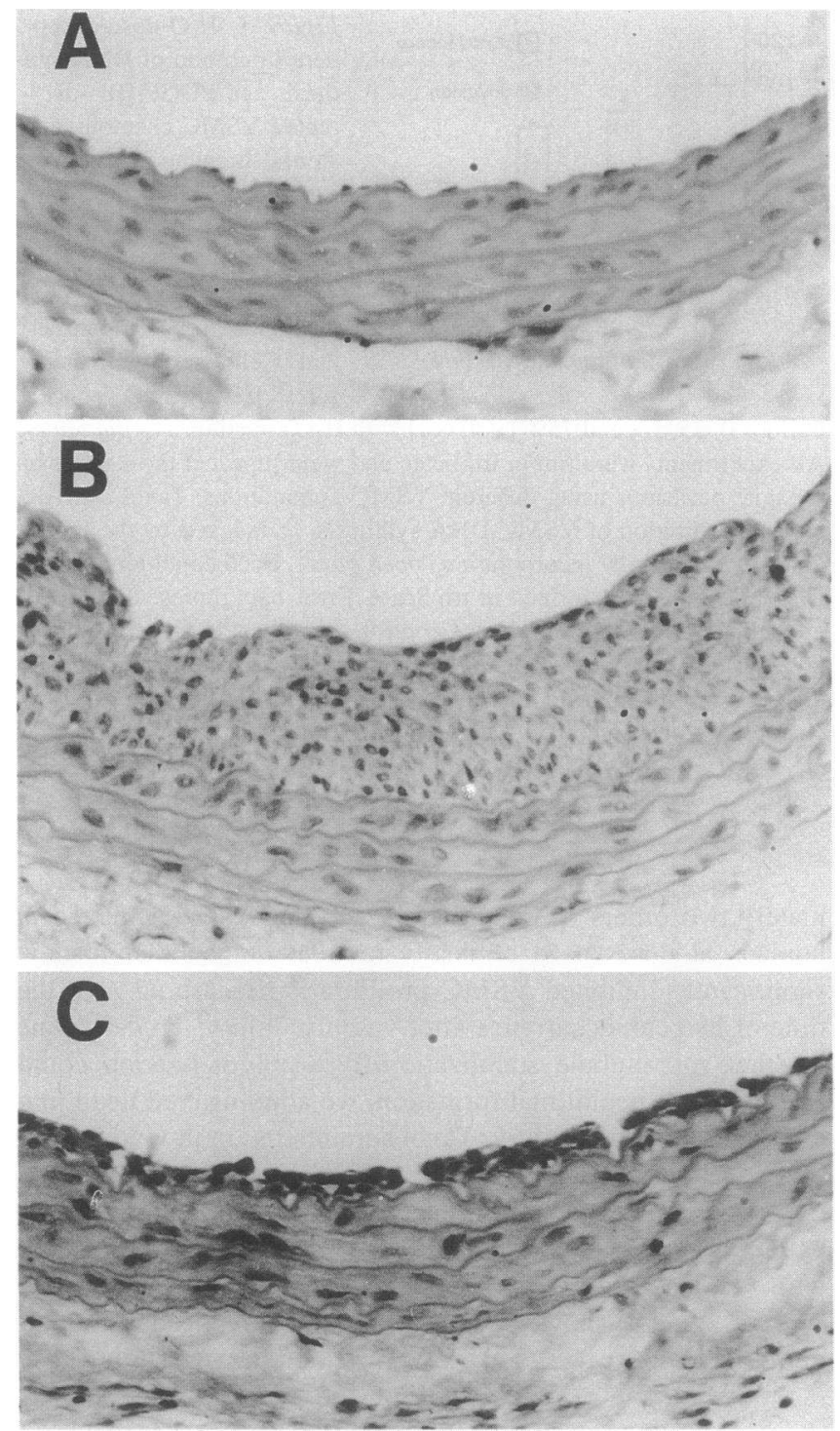

Figure 4. Taxol inhibits the accumulation of intimal smooth muscle cells $11 \mathrm{~d}$ after balloon catheter injury of rat carotid artery. The animals were treated with $2 \mathrm{mg} / \mathrm{kg}$ body weight taxol in vehicle (control animals were treated with vehicle alone) $2 \mathrm{~h}$ after the injury and daily for the next $4 \mathrm{~d}$. Representative hematoxylin- and eosin-stained cross sections from $(A)$ uninjured, $(B)$ vehicle-treated, injured, and $(C)$ taxol-treated, injured rat carotid arteries. $\times 240$.

fibroproliferative lesion after arterial injury, making them particularly strategic targets to influence the outcome.

Based on the in vitro sensitivity of cultured human VSMCs to form taxol-induced microtubule polymerization, it may be possible to predict human clinical responses to these agents after arterial injury, as is true for certain leukemias $(38,39)$. Although the in vivo systemic taxol dose used in these experiments (yielding peak levels of 50-60 nM and trough plasma levels substantially lower than $20 \mathrm{nM}$ ) is significantly lower than that ordinarily achieved with doses and schedules commonly used to treat human cancers (approximately two orders of magnitude lower), even lower systemic dosing with sustained or even improved efficacy could be possible by combining a pretreatment regimen with the optimal treatment duration.
Table I. Quantitation of the Effect of Taxol on the Accumulation of Intimal Smooth Muscle after Rat Left Common Carotid Artery Balloon Catheter Injury

\begin{tabular}{lccc}
\hline Group & Intima & Media & I/M \\
\hline & $m m^{2}$ & $m m^{2}$ & \\
Vehicle & $0.09 \pm 0.01$ & $0.14 \pm 0.01$ & $0.66 \pm .08$ \\
Taxol & $0.03 \pm 0.01^{*}$ & $0.16 \pm 0.02^{\ddagger}$ & $0.18 \pm .04^{\S}$ \\
\hline
\end{tabular}

The image of each carotid artery $11 \mathrm{~d}$ after injury ( 8 taxol-treated and 10 vehicle-treated) was projected onto a digitizing board. The crosssectional areas of the intima and the media were measured and are presented as the mean \pm SEM. I/M denotes the ratio of intimal to medial areas. ${ }^{*} P<0.0002,{ }^{\ddagger} P=\mathrm{NS},{ }^{\S} P<0.0001$, compared with vehicle, by unpaired $t$ test.
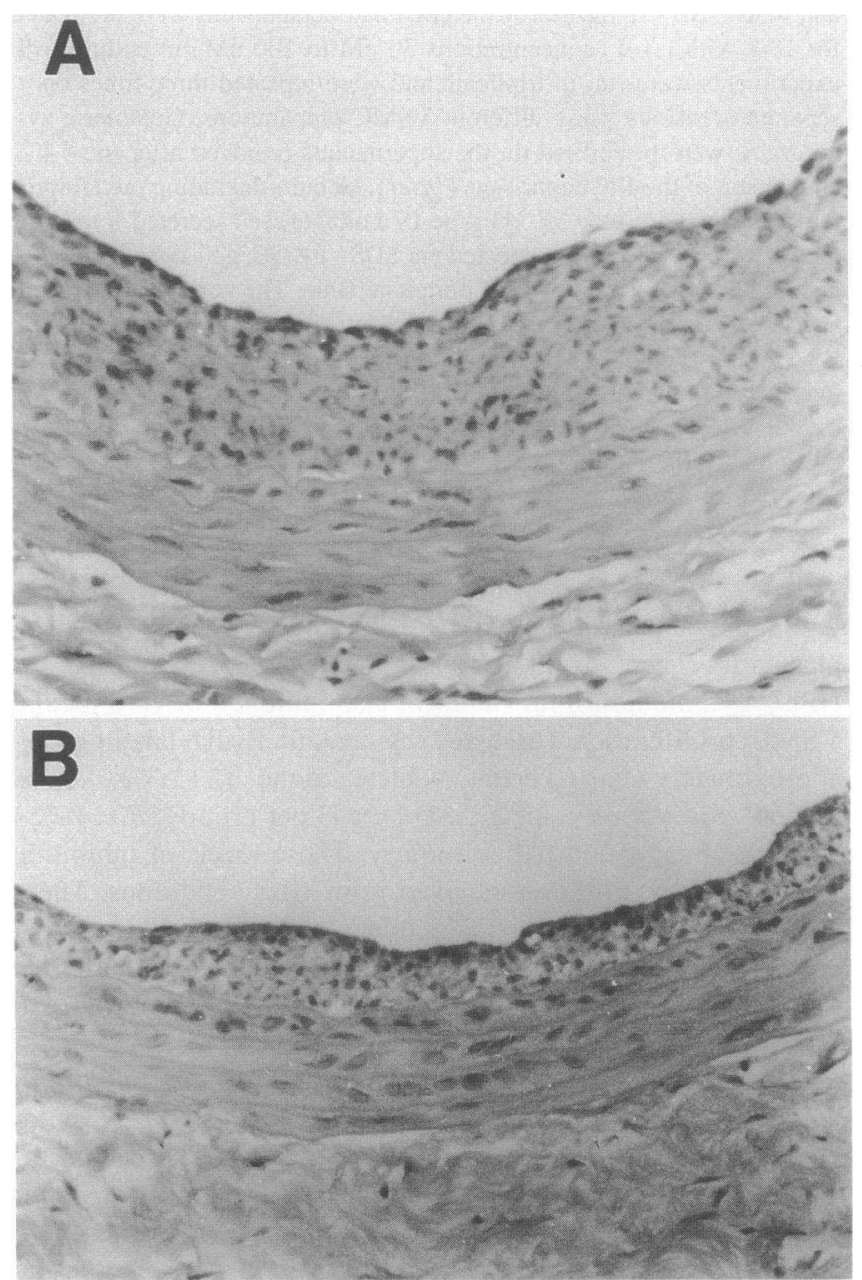

Figure 5. ${ }^{2} \mathrm{H}_{2} \mathrm{O}$ inhibits the accumulation of intimal smooth muscle cells $11 \mathrm{~d}$ after balloon catheter injury of rat carotid artery. The animals were equilibrated with $25 \%{ }^{2} \mathrm{H}_{2} \mathrm{O}$ drinking water for 6 wk before carotid injury (a duration estimated to result in $>23 \%{ }^{2} \mathrm{H}_{2} \mathrm{O}$ replacement of body water) and until the carotid arteries were removed for study. Representative hematoxylin- and eosin-stained cross sections from $(A)$ vehicle-treated, injured and $(B)^{2} \mathrm{H}_{2} \mathrm{O}$-treated, injured rat carotid arteries. See Figure $4 A$ for a representative uninjured carotid section. $\times 240$. 
Table II. Quantitation of the Effect of ${ }^{2} \mathrm{H}_{2} \mathrm{O}$ versus $\mathrm{H}_{2} \mathrm{O}$ on the Accumulation of Intimal Smooth Muscle after Rat Left Common Carotid Artery Balloon Catheter Injury

\begin{tabular}{cccc}
\hline Group & \multicolumn{1}{c}{ Intima } & \multicolumn{1}{c}{ Media } & I/M \\
\hline & \multicolumn{1}{c}{$m^{2}$} & $m^{2}$ & \\
& & $0.16 \pm 0.01$ & $0.87 \pm 0.10$ \\
$\mathrm{H}_{2} \mathrm{O}$ & $0.13 \pm 0.02$ & $0.15 \pm 0.01^{\ddagger}$ & $0.49 \pm 0.02^{8}$ \\
${ }^{2} \mathrm{H}_{2} \mathrm{O}$ & $0.08 \pm 0.01^{*}$ & &
\end{tabular}

The cross-sectional areas of the intima and the media of each carotid artery $11 \mathrm{~d}$ after injury ( $\mathrm{six}^{2} \mathrm{H}_{2} \mathrm{O}$-equilibrated and six $\mathrm{H}_{2} \mathrm{O}$-equilibrated) were measured as in Table I, and the data are presented as the mean \pm SEM. $\mathrm{I} / \mathrm{M}$ denotes the ratio of intimal to medial areas. ${ }^{*} P$ $<0.05,{ }^{\ddagger} P=\mathrm{NS},{ }^{8} P<0.005$, compared with control $\left(\mathrm{H}_{2} \mathrm{O}\right)$, by unpaired $t$ test.

Furthermore, a major goal of therapy after arterial injury is to inhibit the "activated" (i.e., after injury, dedifferentiated) VSMCs, or preferably to prevent activation, via temporary cytostatic mechanisms until the stimuli for growth and migration have abated (rather than causing cytotoxicity resulting in cell death). It is noteworthy that human taxol trials have demonstrated that hematopoietic effects (i.e., reductions in absolute neutrophil and white blood cell counts), the principal toxicity of taxol, begin to develop only when taxol plasma levels are maintained above an apparent threshold of 50-100 nM for durations beyond $\sim 5 \mathrm{~h}(63,64)$, conditions that exceed those used in the present experiments. Thus, the goal of short-term "restenosis-preventive" therapy with limited toxicity may be possible in humans after vascular surgical procedures if human and rat VSMCs are comparably sensitive to taxol.

Although the rat carotid artery injury model remains one of the most convenient and thoroughly investigated models for preliminary investigations into the mechanisms and treatment of restenosis, results from these studies are not necessarily predictive of therapeutic success in humans. The day 11 time point after carotid injury selected to assess neointimal formation in the present study, though predictive of outcome at day 14 (another typical experimental endpoint) in control rats in our laboratory (unpublished data), may not always be completely predictive of results at the longer term. Moreover, intimal hyperplasia, toward which taxol is apparently effective, is only one of several major mechanisms responsible for human restenosis. Additional phenomena, including vessel elastic recoil and wall remodeling, are important features of human restenosis that are probably incompletely addressed in the rat experimental model. Thus, further studies are needed in appropriate larger mammals.

Ultimately, local sustained-release delivery systems may offer the best solution to prevent human restenosis after angioplasty, enabling delivery of high local concentrations of drug and essentially eliminating problems of systemic toxicity. The development of taxol-impregnated biopolymer-coated stenting may offer a realistic approach to address these issues. These results offer the possibility of a chemotherapeutic approach to prevent clinical restenosis after angioplasty and other vascular surgical procedures, including bypass surgery, and possibly to attenuate cardiac transplantation-associated atherosclerosis.

\section{Acknowledgments}

We wish to thank the expert technical assistance of Cynthia Nater.

\section{References}

1. Dustin, P. 1980. Microtubules. Sci. Am. 243:66-76.

2. Carney, D. H., K. L. Crossin, R. Ball, G. M. Fuller, T. Albrecht, and W. C. Thompson. 1986. Changes in the extent of microtubule assembly can regulate initiation of DNA synthesis. Ann. NY Acad. Sci. 466:919-932.

3. Crossin, K. L., and D. H. Carney. 1981. Evidence that microtubule depolymerization early in the cell cycle is sufficient to initiate DNA synthesis. Cell. 23:61-71.

4. Otto, A. M., A. Zumbe, L. Gibson, A. M. Kubler, and L. Jimenez de Asua. 1979. Cytoskeleton-disrupting drugs enhance effect of growth factors and hormones on initiation of DNA synthesis. Proc. Natl. Acad. Sci. USA. 76:64356438.

5. Edelman, G. M. 1976. Surface modulation in cell recognition and cell growth. Science (Wash. DC). 192:218-226.

6. Zhou, R. P., M. Oskarrson, R. S. Paules, N. Schulz, D. Cleveland, and G. F. Vande Woude. 1991. Ability of the c-mos product to associate with and phosphorylate tubulin. Science (Wash. DC). 251:671-675.

7. Verde, F., J. C. Labbe, M. Doree, and E. Karsenti. 1990. Regulation of microtubule dynamics by CDC-2 protein kinase in cell-free extracts of Xenopus eggs. Nature (Lond.). 343:233-238.

8. Maxwell, S. A., S. K. Ames, E. T. Sawai, G. L. Decker, R. G. Cook, and J. S. Butel. 1991. Simian virus 40 large $T$ antigen and p53 are microtubuleassociated proteins in transformed cells. Cell Growth Differ. 2:115-127.

9. Wani, M. C., H. L. Taylor, M. E. Wall, P. Coggon, and A. T. McPhail. 1971. Plant antitumor agents. VI. The isolation and structure of taxol, a novel antileukemic and antitumor agent from Taxus brevifolia. J. Am. Chem. Soc. 93:2325-2327.

10. Schiff, P. B., and S. B. Horwitz. 1980. Taxol stabilizes microtubules in mouse fibroblast cells. Proc. Natl. Acad. Sci. USA. 77:1561-1565.

11. Schiff, P. B., J. Fant, and S. B. Horwitz. 1979. Promotion of microtubule assembly in vitro by taxol. Nature (Lond.). 277:665-667.

12. Rowinsky, E. K., L. A. Cazenave, and R. C. Donehower. 1990. Taxol: a novel investigational antimicrotubule agent. J. Natl. Cancer Inst. 82:1247-1259.

13. Einzig, A. I., P. H. Wiernik, J. Sasloff, C. D. Runowicz, and G. L. Goldberg. 1992. Phase II study and long-term follow-up of patients treated with taxol for advanced ovarian adenocarcinoma. J. Clin. Oncol. 10:1748-1753.

14. McGuire, W. P., E. K. Rowinsky, N. B. Rosenshein, F. C. Grumbine, D. S. Ettinger, D. K. Armstrong, and R. C. Donehower. 1989. Taxol: a unique antineoplastic agent with significant activity in advanced ovarian epithelial neoplasms. Ann. Intern. Med. 111:273-279.

15. Einzig, A. I., H. Hochster, P. H. Wiernik, D. L. Trump, J. P. Dutcher, E. Garowski, J. Sasloff, and T. J. Smith. 1991. A phase II study of taxol in patients with malignant melanoma. Invest. New Drugs. 9:59-64.

16. Holmes, F. A., R. S. Walters, R. L. Theriault, A. D. Forman, L. K. Newton, M. N. Raber, A. U. Buzdar, D. K. Frye, and G. N. Hortobagyi. 1991. Phase II trial of taxol, an active drug in the treatment of metastatic breast cancer. J. Natl. Cancer Inst. 83:1797-1805.

17. Ferrell, M., V. Fuster, H. K. Gold, and J. H. Chesebro. 1992. A dilemma for the 1990 s. Choosing appropriate experimental animal model for the prevention of restenosis. Circulation. 85:1630-1631.

18. Sjölund, M., U. Hedin, T. Sejersen, C. H. Heldin, and J. Thyberg. 1988. Arterial smooth muscle cells express platelet-derived growth factor (PDGF) A chain mRNA, secrete a PDGF-like mitogen, and bind exogenous PDGF in a phenotype- and growth state-dependent manner. J. Cell Biol. 106:403-413.

19. Pauly, R. R., A. Passaniti, R. Monticone, L. Cheng, C. Weinstein, L. Smith, N. Papadopoulos, E. G. Lakatta, and M. T. Crow. 1994. Invasion of the extracellular matrix by vascular smooth muscle cells requires $72 \mathrm{kD}$ type IV collagenase and is inhibited by differentiation. Circ. Res. 75:41-54.

20. Dartsch, P. C., G. Bauriedel, I. Schinko, H. D. Weiss, B. Hofling, and E. Betz. 1989. Cell constitution and characteristics of human atherosclerosis plaques selectively removed by percutaneous atherectomy. Atherosclerosis. 80:149-157.

21. Reidy, M. A. 1985. A reassessment of endothelial injury and arterial lesion formation. Lab. Invest. 53:513-520.

22. Clowes, A. W., M. A. Reidy, and M. M. Clowes. 1983. Kinetics of cellular proliferation after arterial injury. I. Smooth muscle growth in the absence of endothelium. Lab. Invest. 49:327-333.

23. Reidy, M. A., and S. M. Schwartz. 1981. Endothelial regeneration. III. Time course of intimal changes after small defined injury to rat aortic endothelium. Lab. Invest. 44:301-308.

24. Friedman, R. J., R. J. Stemerman, B. Wenz, S. Moore, J. Gauldie, M. Gent, M. L. Tiell, and H. Spaet. 1977. The effect of thrombocytopenia on experimental arteriosclerotic lesion formation in rabbits. Smooth muscle cell proliferation and re-endothelialization. J. Clin. Invest. 60:1191-1201.

25. Harker, L. A., R. Ross, S. J. Slichter, and C. R. Scott. 1976. Homocystineinduced arteriosclerosis. The role of endothelial cell injury and platelet response in its genesis. J. Clin. Invest. 58:731-741.

26. Stemerman, M. B., and R. Ross. 1972. Experimental arteriosclerosis. I. Fibrous plaque formation in primates, an electron microscopic study. J. Exp. Med. 136:769-789. 
27. Baumgartner, H. R., and A. Studer. 1966. Effects of vascular catheterization in normo- and hypercholesteremic rabbits. Pathol. Microbiol. 29:393-405.

28. O'Brien, E. R., C. E. Alpers, D. K. Stewart, M. Fergusen, N. Tran, D. Gordon, E. P. Benditt, T. Hinohara, J. B. Simpson, and S. M. Schwartz. 1993. Proliferation in primary and restenotic coronary atherectomy tissue. Implications for antiproliferative therapy. Circ. Res. 73:223-231.

29. Gordon, D., M. A. Reidy, E. P. Benditt, and S. M. Schwartz. 1990. Cell proliferation in human coronary arteries. Proc. Natl. Acad. Sci. USA. 87:46004604 .

30. Pauly, R. R., A. Passaniti, M. Crow, J. L. Kinsella, N. Papadopoulos, R. Monticone, E. G. Lakatta, and G. R. Martin. 1992. Experimental models that mimic the differentiation and dedifferentiation of vascular cells. Circulation. 86(Suppl. III) :68-73.

31. Albini, A., Y. Iwamoto, H. K. Kleinman, G. R. Martin, S. A. Aaronson, J. M. Kozlowski, and R. N. McEwan. 1987. A rapid in vitro assay for quantitating the invasive potential of tumor cells. Cancer Res. 47:3239-3245.

32. Kleinman, H. K., M. L. McGarvey, J. R. Hassell, V. L. Star, F. B. Cannon, G. W. Laurie, and G. R. Martin. 1986. Basement membrane complexes with biological activity. Biochemistry. 25:312-318.

33. Lindner, V., N. E. Olsen, A. W. Clowes, and M. A. Reidy. 1992. Inhibition of smooth muscle proliferation in injured rat arteries: interaction of heparin with basic fibroblast growth factor. J. Clin. Invest. 90:2044-2049.

34. Longnecker, S. M., R. C. Donehower, A. E. Cates, T. L. Chen, R. B. Brundrett, L. B. Grochow, D. S. Ettinger, and M. Colvin. 1986. High performance liquid chromatographic assay for taxol (NSC 125973) in human plasma and urine pharmacokinetics in a phase I trial. Cancer Treat. Rep. 71:53-59.

35. Stearns, M. E., and M. Wang. 1992. Taxol blocks processes essential for prostate tumor cell (PC-3 ML) invasion ani metastases. Cancer Res. 52:37763781.

36. Roberts, J. R., D. C. Allison, R. C. Donehower, and E. K. Rowinsky. 1990. Development of polyploidization in taxol-resistant human leukemia cells in vitro. Cancer Res. 50:710-716.

37. Roberts, J. R., E. K. Rowinsky, R. C. Donehower, J. Robertson, and D. C. Allison. 1989. Demonstration of the cell cycle positions of taxol-induced "asters" and "bundles" by sequential measurements of tubulin immunofluorescence, DNA content, and autoradiographic labeling of taxol-sensitive and -resistant cells. $J$. Histochem. Cytochem. 37:1659-1665.

38. Rowinsky, E. K., P. J. Burke, J. E. Karp, R. W. Tucker, D. S. Ettinger, and R. C. Donehower. 1989. Phase I and pharmacodynamic study of taxol in refractory acute leukemias. Cancer Res. 49:4640-4647.

39. Rowinsky, E. K., R. C. Donehower, R. J. Jones, and R. W. Tucker. 1988. Microtubule changes and cytotoxicity in leukemic cell lines treated with taxol. Cancer Res. 48:4093-4100.

40. Wang, M., and M. E. Stearns. 1988. Blocking of collagenase secretion by estramustine during in vitro tumor cell invasion. Cancer Res. 48:6262-6271.

41. Stearns, M. E., and M. Wang. 1991. Regulation of kinesin expression and type IV collagenase secretion in invasive human prostate PC-3 tumor sublines. Cancer Res. 51:5866-5875.

42. Thomson, J. F. 1963. Biological Effects of Deuterium. Pergamon Press, Oxford.

43. Itoh, T. J., and H. Sato. 1984. The effects of deuterium oxide $(2 \mathrm{H} 2 \mathrm{O})$ on the polymerization of tubulin in vitro. Biochim. Biophys. Acta. 800:21-27.

44. Olmsted, J. B., and G. G. Borisy. 1973. Characterization of microtubule assembly in porcine brain extracts by viscometry. Biochemistry. 12:4282-4289.

45. Takahashi, T. C., and H. Sato. 1984. Yields of tubulin paracrystals, vinblas- tine-crystals, induced in unfertilized and fertilized sea urchin eggs in the presence of $\mathrm{D}_{2} \mathrm{O}$. Cell Struct. Funct. 9:45-52.

46. Ross, R. 1993. The pathogenesis of atherosclerosis: a perspective for the 1990s. Nature (Lond.). 362:801-807.

47. Ferns, G. A., E. W. Raines, K. H. Sprugel, A. S. Motani, M. A. Reidy, and R. Ross. 1991. Inhibition of neointimal smooth muscle accumulation afte angioplasty by an antibody to PDGF. Science (Wash. DC). 253:1129-1132.

48. Raines, E. W., D. F. Bowen-Pope, and R. Ross. 1990. Platelet-derived growth factor. In Handbook of Experimental Pharmacology: Peptide Growth Factors and Their Receptors. M. B. Sporn and A. B. Roberts, editors. SpringerVerlag, Berlin. 173-262.

49. Heldin, C. H., and B. Westermark. 1990. Platelet-derived growth factor mechanism of action and possible in vivo function. Cell Reg. 1:555-566.

50. Burgess, W. H., and T. Maciag. 1989. The heparin-binding (fibroblast) growth factor family of proteins. Annu. Rev. Biochem. 80:575-606.

51. Klagsbrun, M., and E. R. Edelman. 1989. Biological and biochemica properties of fibroblast growth factors. Implications for the pathogenesis of atherosclerosis. Arteriosclerosis. 9:269-278.

52. Hart, C. E., J. W. Forstrom, J. D. Kelly, R. A. Seifert, R. A. Smith, R. Ross, M. J. Murray, and D. F. Bowen-Pope. 1988. Two classes of PDGF receptor recognize different isoforms of PDGF. Science (Wash. DC). 240:1529-1531.

53. Folkman, J., M. Klagsbrun, J. Sasse, M. Wadzinski, D. Ingber, and I. Vlodavsky. 1988. A heparin-binding angiogenic protein-basic fibroblast growth factor-is stored within basement membrane. Am. J. Pathol. 130:393-400.

54. Ross, R., E. W. Raines, and D. F. Bowen-Pope. 1986. The biology of platelet-derived growth factor. Cell. 46:155-169.

55. Leonard, P. J., and J. M. Mullins. 1987. D2O induced alterations of mitosis in PtK1 cells. Exp. Cell Res. 172:204-211.

56. Burgess, J., and D. H. Northcote. 1969. Action of colchicine and heavy water on the polymerization of microtubules. J. Cell Sci. 5:433-451.

57. Lamprecht, J., D. Schroeter, and N. Paweletz. 1991. Derangement of microtubule arrays in interphase and mitotic PtK2 cells treated with deuterium oxide (heavy water). J. Cell Sci. 98:463-473.

58. Otto, A. M., and L. Jimenez de Asua. 1983. Microtubule-disrupting agents can independently affect the prereplicative period and the entry into $S$ phase stimulated by prostaglandin F2 alpha and fibroblastic growth factor. J. Cell. Physiol. 115:15-22.

59. Otto, A. M., M. O. Ulrich, A. Zumbe, and L. Jimenez de Asua. 1981 Microtubule-disrupting agents affect two different events regulating the initiation of DNA synthesis in Swiss 3T3 cells. Proc. Natl. Acad. Sci. USA. 78:3063-3067.

60. Teng, M. H., J. C. Bartholomew, and M. J. Bissell. 1977. Synergism between anti-microtubule agents and growth stimulants in enhancement of cel cycle traverse. Nature (Lond.). 268:739-741.

61. Rasmussen, S. A., and R. P. Davis. 1977. Effect of microtubular antagonists on lymphocyte mitogenesis. Nature (Lond.). 269:249-251.

62. Rowinsky, E. K., M. Wright, B. Monsarrat, G. J. Lesser, and R. C Donehower. 1993. Taxol: pharmacology, metabolism, and clinical implications. Cancer Surveys 17:283-304.

63. Huizing, M. T., A. C. Keung, H. Rosing, V. van der Kuij, W. W. ten Bokkel Huinink, I. M. Mandjes, A. C. Dubbelman, and J. H. Beijnen. 1993. Pharmacokinetics of paclitaxel and metabolites in a randomized comparative study in platinum-pretreated ovarian cancer patients. J. Clin. Oncol. 11:2127-2135.

64. Gianni, L., C. M. Kearns, A. Giani, G. Capri, L. Vigano, A. Locatelli, G. Bonadonna, and M. J. Egorin. 1995. Nonlinear pharmacokinetics and metabolism of paclitaxel and its pharmacokinetic/pharmacodynamic relationships in humans. J. Clin. Oncol. 13:180-190. 